\title{
Study on the evaluation of aerobics performance of education professional students
}

\author{
Yan Zhou \\ JiangXi Vocational of Industry \& Engineering, Jiangxi 337055, China
}

Key words: Sports education major; Aerobics; Evaluation of student performance

\begin{abstract}
Since the aerobics was introduced into China, deeply love and favor of college students, many colleges and universities are gradually opened aerobics classes, participate in the number of students in learning and growing. Despite the calisthenics course has been popularized and development, but in the aerobics course in physical education major, the students' academic performance evaluation has been influenced by traditional physical education teaching thought, some shortcomings and deficiencies, it is necessary to reform and innovation in the form of the evaluation in order to promote the development of the aerobics course, and promote the improvement of teaching quality.
\end{abstract}

\section{Introduction}

Since aerobics introduction in the 1980s, it has been popular among college students and has become one of the important sports in universities. At present, the part of physical education major in colleges and universities has also actively opened aerobics curriculum, evaluation of aerobics mass movements, aerobics basic pace and routines, editing the aerobics, Latin aerobics teaching activities, thus greatly promoted the development and popularization of aerobics in China. However, there are many problems in the evaluation of the performance of aerobics courses, and the scientific and rationality of the evaluation methods of student performance need to be improved. Therefore, only to construct a set of system, scientific calisthenics performance evaluation system, can really inspire the enthusiasm and initiative of students to participate in aerobics training base, in order to accurately grasp the training of the students and the teaching effect, on the basis of innovation subject teaching contents, teaching methods and teaching mode.

\section{Definition of relevant concepts}

\subsection{The concept of aerobics}

Aerobics is an emerging sport, which is an aerobic exercise or aerobic dance. Most experts and scholars believe that aerobics is an integrated gymnastics, dance, and music, which is based on aerobic exercise, and features sports activities characterized by health, strength and beauty. The foundation and substance of calisthenics is cardio or cardio. With a movement of the body's aerobic system provides energy form, its movement is characterized by a certain duration, the systemic activity of low intensity, the main influence practitioners of cardiopulmonary function, is the foundation of the endurance quality.

\subsection{The concept of student achievement evaluation}

Student achievement evaluation is based on certain criteria to evaluate students' academic progress and behavioral change. Tests, quizzes, and measurements are used to evaluate students' 
performance, and the evaluation of achievement is based on measuring the individual development and learning effect of the students. The academic evaluation is important for both teachers and students, and the teacher can control the students' knowledge in order to adjust them in the future teaching. For students, it can be used to check their deficiencies in their study, and how far from their expectations, the direction for future learning.

\section{The current status of the evaluation of aerobics performance of education professional students in colleges and universities}

At present our country ordinary university sports education professional evaluation of aerobics student achievement goal shows the characteristics of diversification, most schools in the regular classroom teaching task, on the basis of the basic goals, all hope that through the aerobics course grade evaluation activity to test students' study effect, motivating students to learn, to sum up the experiences of teaching goal, there is also a part of the school hopes to clear direction and selection of outstanding students study;

The aerobics course student achievement evaluation content involves the movement routines, theoretical knowledge, creating and ability, aesthetic ability, teaching ability, organization and management ability, sports training and classroom learning attitude and performance in many aspects, such as content, presents the diversification, comprehensive and systematic characteristics, but there is a series of problems to be solved, including the performance evaluation content system is imperfect, evaluation standard and optional the gender is big, the incentive effect is not obvious and so on.

The universities sports education professional aerobics course is designed for the student performance evaluation target and evaluation content, set up a corresponding evaluation standards, and through the usual assessment and result assessment, qualitative assessment and quantitative evaluation, and the combination of theory and practice of examination about the way of specific performance evaluation activities; Some colleges and universities also adopt the traditional methods of score control, oral evaluation, incentive and punishment, etc., to guarantee the quality and efficiency of the teaching and performance evaluation of aerobics.

Now most schools will gymnastics theory, routine, creative, referees to knowledge, teaching methods, organization and management ability, sports training, learning attitude and classroom performance and other aspects, in order to assess students' final course grade, and implement the effective guidance of aerobics learning behavior for students.

\section{Problems in the evaluation of calisthenics performance}

Performance evaluation content system is imperfect, for students of aerobics teaching organization and management ability, not enough attention aerobics theoretical knowledge level, is not conducive to sports education specialized "to cultivate sports education talent as the core" to achieve the goals of talents cultivation.

Performance evaluation standard optional the gender is big, the students' learning attitude, classroom performance and aerobics aesthetic aspects of the performance evaluation standard completely to determine by the teacher according to their own subjective cognition, class of the aerobics movement routines, aerobics plait, aerobics referees and content such as aerobics teaching and management performance evaluation standards in the process of actual execution form too. 
Performance evaluation incentive and guiding role to play enough, most of the schools are fractions quantitative evaluation, the single way to control the lack of aerobics a variety of ability training effect evaluation of diversity and pertinence.

\section{Evaluation of performance evaluation of aerobics}

Improve the content system of aerobics evaluation. It should pay attention to design evaluation contents and indexes from four aspects, such as personal cultivation, theoretical connotation, skill level and teaching practice ability.

Based on the professional sports education and the characteristics of the students, construct the scientific and systematic performance evaluation index assignment system, the different evaluation index in the assignment system of ascension occupies proportion and fit and rationality of training objectives;

According to the teaching objectives, teaching contents, teaching methods and teaching plan of the school's aerobics course, the evaluation index system of scientific achievement evaluation is constructed.

Improve the standardization and operability of performance evaluation criteria, ensure that the probability of system error can be reduced in the evaluation process and avoid errors and incidental errors.

To further enrich and improve the incentive factors in the evaluation system of student achievement, to give full play to the incentive, stratification and guiding value of the evaluation.

\section{Suggestions on the evaluation of aerobics performance of education professional students in normal universities}

The current our country sports education professional aerobics teachers should based on the characteristics of physical education, strengthen the theory of aerobics, aerobics teaching methods and teaching management, and other content of teaching and evaluation activities, so that the students can be better in the future work in the aerobics teaching and management.

Sports education professional led to strengthen the publicity and education activities of aerobics teachers, deepening it's to develop and implement a recognition of the importance of aerobics course grade evaluation criteria, requires teachers to students in detail before the class learning attitude, classroom performance, aesthetic ability and so on performance evaluation content, the mode of evaluation and evaluation criteria, in the class to be strict, fair and just to complete each content seriously performance evaluation and record activities.

Sports education professional teaching and research office and school academic affairs office should strengthen the evaluation of students' performance evaluation and evaluation criteria for the teaching program of aerobics courses submitted by teachers; Moreover, in the course of daily teaching and teaching of calisthenics, the supervision and investigation of teachers should be strengthened.

Aerobics teachers of physical education should be aimed at specific curriculum evaluation content set a richer, more diverse rewards and punishments measures, further refine the result evaluation criteria, in the process of implement evaluation standard is strict earnest, fair and just as much as possible, so as to further enrich and perfect the incentive factors in the evaluation system of student performance. 


\section{References}

[1] Zhou-Le. Study on the evaluation of sports option in the general college of liaoning province [D]. Jilin: northeast normal university, 2009.

[2]Zhu xinxin. Research on competitive calisthenics system system [D]. Suzhou: suzhou university, 2010.

[3] Li-Gao. Study on the evaluation system of students' academic performance in college PE [D]. Beijing: Beijing sports university, 2008.

[4] Du XiuJuan. Research on the cultivation of aerobics teaching ability of education professional students in the normal university of gansu province [D]. Lanzhou: northwest normal university, 2014.

[5]He XuHui. Education, education professional student performance evaluation system research [D]. Shenyang: shenyang institute of physical education, 2010.

[6] Wang HaiChao. Investigation and countermeasure research on the current situation of teaching of aerobics in education undergraduate program in henan province [D]. Kaifeng: henan university, 2010. 